\title{
TRAJETÓRIAS DE UM CLÁSSICO: AUTORIAS, EDIÇÕES E LEITURAS DO PAVÃO MISTERIOSO
}

\author{
Antonio Helonis Borges Brandão ${ }^{1}$
}

Resumo: O presente trabalho percorre no tempo $O$ romance do pavão misterioso, enredo poético de José Camelo de Melo Resende que, recriado, foi publicado (na década de 1920, sem data precisa) em formato de folheto por João Melchíades Ferreira da Silva. Discutindo-o sob o ponto de vista da forma literária, autoria, materialidade e usos diferenciados, objetiva compreender a produção de sentidos sobre a obra supracitada quando materializada em formatos e edições diversas. Para tanto utiliza-se do cabedal teórico da história do livro e da leitura, segundo Roger Chartier (1990; 2020), e da ideia de movência, conforme a pensou Paul Zumthor (1998). O tipo de análise que propõe - que associa história e literatura - reflete sobre o complexo circuito cultural de produção, circulação e consumo do que hoje está estabelecido na forma literária do cordel brasileiro, através de práticas, representações e usos que o ressignificam em contextos distintos. Palavras-chave: Apropriação. Cordel. Movência. Práticas. Representações.

\section{TRAJECTORIES OF A CLASSIC: AUTHORSHIP, EDITIONS AND READINGS OF THE PAVÃO MISTERIOSO}

\begin{abstract}
The present paper goes through in time $\mathrm{O}$ romance do pavão misterioso, poetic plot by José Camelo de Melo Resende that, recreated, was published (in the 1920s, without precise date) in brochure format by João Melchíades Ferreira da Silva. Discussing it from the point of view of literary form, authorship, materiality and differentiated uses, aims to understand the production of meanings about the aforementioned work when materialized in various formats and editions. Therefore, it uses the theoretical leather of history of book and reading, according to Roger Chartier (1990; 2020), and the idea of moving, as Paul Zumthor (1998) thought. The type of analysis he proposes - which associates history and literature - reflects about complex cultural circuit of production, circulation and absorption of what nowadays established in the literary form of Brazilian cordel, through practices, representations and uses which signify it in different contexts.
\end{abstract}

Keywords: Appropriation. Cordel. Movement. Practices. Representations.

\section{TRAYECTORIAS DE UN CLÁSICO: AUTORÍA, EDICIONES Y LECTURAS DEL PAVÃO MISTERIOSO}

Resumen: La presente obra pasa en el tiempo $O$ romance do pavão misterioso, trama poética de José Camelo de Melo Resende que, recreada, fue publicada (en la década de 1920, sin fecha precisa) en formato de folleto por João Melchíades Ferreira da Silva. Discutirlo desde el punto de vista de la forma literaria, autoría, materialidad y usos diferenciados, tiene como objetivo comprender la producción de significados sobre la citada obra cuando se materializa en diversos formatos y ediciones. Para ello, utiliza el cuero teórico de la historia del libro y la lectura, según Roger Chartier (1990; 2020), y la idea de moverse, como pensaba Paul Zumthor (1998). El tipo de análisis que propone - que asocia historia y literatura - reflexiona sobre el complejo circuito cultural de producción, circulación y consumo de lo que hoy se establece en la forma literaria del

\footnotetext{
${ }^{1}$ Possui graduação em História pela Universidade Estadual do Ceará (1994), mestrado em História Social pela Universidade Federal do Rio de Janeiro (2000) e doutorado em História Social pela Universidade Federal Fluminense (2020). É professor de História na Secretaria de Educação do Estado do Ceará SEDUC, atividade que exerce no Centro de Documentação e Informação Educacional (CDIE) e onde é um dos editores da Revista DoCEntes.
} 
cordel brasileño, a través de prácticas, representaciones y usos que lo significan en diferentes contextos.

Palabras clave: Apropiación. Cordel. Muévete. Prácticas. Representaciones.

\section{Prelúdio de um voo "misterioso"}

A gênese da literatura de cordel situa-se num tempo largo de influências não muito bem definidas, sendo um misto de enredos entrelaçados por histórias e poéticas que se pautam por origens variadas. No Brasil, é nas duas últimas décadas do séc. XIX que surge os contornos de um sistema editorial bem próprio, caracterizado pelo formato gráfico de brochura e editadas em pequenas tipografias de modo artesanal. No que se refere à forma, são narrativas poéticas, rimadas e metrificadas em sextilhas, setilhas e décimas, enredadas em tramas os mais diversos e com a cor local. Nas primeiras duas décadas do século seguinte o circuito de produção, circulação e consumo dos folhetos de versos, uma das muitas denominações utilizadas para se referir ao impresso, se consolida, sob um modelo que só pode ser definido como móvel e à margem da literatura canônica já consagrada pelas escolas literárias então vigentes. Desde então o formato de produção artesanal, que se associa à forma poética e à venda volante, é difundindo - inicialmente a partir do Nordeste brasileiro -, ao ponto de hoje ser reconhecido como patrimônio imaterial ${ }^{2}$ e gênero literário brasileiro ${ }^{3}$.

Entender a distinção entre a materialidade do formato e dos seus usos - o resultado da conjunção dos ofícios múltiplos de autores, editores, distribuidores e folheteiros (os vendedores ambulantes de folhetos de verso) - em relação à forma - expressa em

\footnotetext{
${ }^{2} \mathrm{O}$ processo de reconhecimento da literatura de cordel como patrimônio imaterial da cultura brasileira, iniciado em 22 de fevereiro de 2010, teve por proponente a Academia Brasileira da Literatura de Cordel (ABLC), com o apoio do Centro Nacional de Folclore e Cultura Popular (CNFCP). Através de dossiê, coordenado pela Profa. Dra. Rosilene Alves de Melo, da Universidade Federal da Paraíba (UFPB), fez-se o levantamento das práticas relativas ao ofício, de toda a área de concentração no país, além do levantamento sobre o contexto histórico de produção, circulação e consumo. O relatório final ficou a cargo do professor emérito da Faculdade de Filosofia, Letras e Ciências Humanas (FFLCH) da Universidade de São Paulo (USP), Dr. Ulpiano Toledo Bezerra de Menezes, conselheiro titular e representante da sociedade civil na instituição. Em Reunião Ordinária do Conselho Consultivo do Instituto do Patrimônio Histórico e Artístico Nacional (IPHAN), realizada em 19 de setembro de 2018, o relator proferiu o seu parecer provisório, que foi referendado por unanimidade pelo colegiado. Ver: INSTITUTO do Patrimônio Histórico e Artístico Nacional. Disponível em: $<$ http://portal.iphan.gov.br/pagina/detalhes/426;http://portal.iphan.gov.br/noticias/detalhes/4833/literatura -de-cordel-e-reconhecida-como-patrimonio-cultural-do-brasil>. Acesso em: 23 jun. 2021.

${ }^{3}$ Sobre estudos recentes que abordam o cordel como gênero literário, ver: BRANDÃO, Antonio Helonis Borges. Apropriações instituídas e a subversão do popular: usos, formatos e poética do cordel literatura. 2020. Tese (Doutorado em História Social). Instituto de História, Universidade Federal Fluminense, Niterói, 2020; LUCENA, Bruna Paiva de. Espaços em disputa: o cordel e o campo literário brasileiro. 2010. 88 f. Dissertação (Mestrado) - Instituto de Letras, Universidade de Brasília, Brasília, 2010.
} 
representações simbólicas enredadas em uma poética que compõem um modelo literário - é um dos objetivos aqui almejados. Por sua vez, a análise a ser feita também reflete sobre como o texto em pauta se apresenta inserido em diferentes contextos (espaçotempo) e é movente dentro do sistema editorial e literário do cordel brasileiro, que se faz sob “incessantes variações recriadoras” (ZUMTHOR, 2018, p. 61) $)^{4}$.

O romance do pavão misterioso ou $O$ pavão misterioso é a obra5, narrativa poética e modelo matricial que se fez materializada em diversos impressos e edições, de onde advêm os textos aqui utilizados para a discussão da movência em aspectos formais e materiais do gênero literário do cordel brasileiro. Assim, através da historicização de um dos textos canônicos mais conhecidos - escolhido entre dezenas de milhares de todos os já produzidos, que circularam e foram lidos -, se discute as recriações e transformações do gênero literário.

Deste modo, nos quase 100 anos estimados do início desse voo ainda misterioso em grande parte de sua trajetória enviesada, é um exercício complexo refazer o percurso editorial da obra, dos seus vários textos e diferentes leituras. Seja pelas sutilezas e interpretações distintas que podem ser dadas ao circuito percorrido pela obra, a partir da sua indefinida autoria, como também pela trajetória editorial que comporta muitas lacunas e questões ainda não esgotadas. Assim, através de diversas edições, releituras e usos que se fizeram dela ao longo desse largo tempo, se busca refletir sobre as reiterações, mudanças ou permanências que se apresentam e movem o gênero poético.

Para tanto a análise reflexiva proposta também se utiliza das ferramentas da história do livro e da leitura que, segundo Roger Chartier, permitem fazer "[...] uma história social dos usos e das interpretações, relacionados às suas determinações fundamentais e inscritas nas práticas específicas que a produzem" (CHARTIER, 1990, p. 56). Assim, sob o ponto de vista das autorias, edições, circulação, leituras e releituras, discute-se as práticas, representações e usos que estabelecem a tensão na “[...] identidade

\footnotetext{
${ }^{4}$ Nos utilizamos da ideia de "movência", conforme pensada por Paul Zumthor como "reiteração" mediada pela performance e pela leitura, para discutir as transformações pelas quais passou o cordel brasileiro na forma, no formato e no próprio circuito editorial em constante atualização. Ver: ZUMTHOR, Paul. Performance, recepção, leitura. São Paulo: Ubu Editora, 2018. p. 57-68.

${ }^{5}$ Muito embora $O$ romance do pavão misterioso, título genérico da obra matriz que é utilizado ao longo do artigo, seja considerado um dos mais conhecidos, relacionados ao gênero poético do cordel brasileiro, não há qualquer precisão documental a respeito do ano e local em que foi publicado pela primeira vez pelos poetas a quem se atribui a sua autoria. A própria autoria, como se verá ao longo do artigo, é dúbia e controversa. Assim, optou-se por não o referenciar quando pensado na sua permanência como obra, mas somente quando tratado como texto materializado em uma edição conhecida e disponível.
} 
perpetuada, reconhecível, desmaterializada das obras [...]" (CHARTIER, 2020, p. 19). Ao mesmo tempo em que se aponta as transformações e atualizações da obra, a exemplo de $O$ romance do pavão misterioso, nos textos advindos da " [...] mobilidade assegurada pela multiplicidade de suas leituras, das suas formas materiais, dos seus modos de atribuições [...]" (CHARTIER, 2020, p. 19).

\section{Entendendo a gênese do texto e a questão da autoria}

Há indícios de que a matriz do enredo e os motivos que originam e sustentam $O$ romance do pavão misterioso estaria fincados na oralidade e no domínio público das formas poéticas que se perpetuam no tempo remoto das oralidades. Notadamente são os estudos de folclore, realizados no Brasil de modo pioneiro por Silvio Romero (1977), no final do XIX, e depois por Gustavo Barroso (1912; 1921), Rodrigues de Carvalho (1903), Leonardo Mota $(1921 ; 1925)$, dentre outros, nas primeiras décadas do XX, que primeiro advogam que há um imenso manancial de influências diversas para a criação do romanceiro de histórias versificadas, do que então intitularam de poesia popular.

Depois deles, Câmara Cascudo também apresenta a poesia popular sob influências diversas das vozes, em Literatura oral no Brasil (1952), e das escritas, em Cinco livros do povo (1953), que se praticava no Brasil Colônia. Seja mapeando a presença das histórias maravilhosas das "mil e uma noites" - caso da História da Donzela Teodora (CASCUDO, 1953, p. 46-48) -, aqui chegadas por meio indireto e sob as influências deixadas pelos conquistadores árabes na península ibérica; constatando forte permanência das xácaras e do romanceiro português - a exemplo da Imperatriz Porcina (CASCUDO, 1953, pp. 283-285) -; além de reconhecer a grande difusão que teve no Brasil os romances medievais do ciclo carolíngio - como o de Roberto do Diabo (CASCUDO, 1953, p. 171175) -, o que os estudos do folclorista potiguar ressaltam é que são muitos os mananciais dos enredos difundidos na criação das histórias versificadas publicadas em folhetos.

No Brasil, o tipo de enredo poético que se apresenta em uma trama desenvolvida em longas narrativas, envolvendo diversos personagens em uma história que perpassa, quase sempre, pelo amor, a fantasia e a eterna luta entre o bem e o mal, emerge sob as influências citadas já em meados do XIX. Mas só ganha contornos próprios e se consolida em seu formato nas primeiras décadas do século XX. Impresso sob o formato de "folhetos 
em versos"6, o "romance" se difere do "folheto", propriamente dito, por aquele desenvolver o tipo de enredo já citado em uma paginação bem maior, quase sempre com 32 ou mais páginas.

O texto de $O$ pavão misterioso se enquadra na categoria romance, acima citada: é um texto longo, com enredo fantasioso, fictício e foi publicado em 32 páginas em algum momento da década de 1920. A respeito do ano exato em que foi publicado, até hoje não há comprovação documental. No Dicionário Biobibliográfico de repentistas e poetas de bancada, Átila Almeida e José Alves Sobrinho (1978, p. 235) indicam, sem citar a fonte, que o autor do poema é José Camelo de Melo Rezende e que ele foi publicado entre 1927 e 1929.

Quanto ao enredo poético, trata de uma estória fantástica em que um estrangeiro aventureiro, por nome Evangelista, viaja a um país longínquo, ao se apaixonar pela filha única do potentado local depois de conhecê-la em uma fotografia presenteada pelo seu irmão. Mas há um impedimento em conhecê-la, pois ela vivia trancafiada pelo conde, seu pai, em uma torre inacessível e fortemente guarnecida. Assim, resolve roubá-la se servindo de uma máquina voadora em formato de pavão, construída por um sábio construtor de engenhocas. Depois de idas, vindas, disputas, lutas os protagonistas, Evangelista e Creuza se apaixonam, casam-se e tornam-se os monarcas deste reino misterioso.

Talvez o primeiro registro a respeito da obra, sob o ponto de vista de um comentador, seja o do escritor, pesquisador e dos maiores estudiosos dos folhetos de seu tempo, Manoel Cavalcanti Proença (1942), que nos relata, no livro Ribeiras do S. Francisco, ter conhecimento do poema, já editado em brochura e circulando entre os ribeirinhos, por ocasião de uma das suas viagens pelas barrancas do Rio São Francisco (a primeira delas ainda em 1924). Ainda faz um resumo do enredo do poema, mas não

\footnotetext{
${ }^{6}$ Há um léxico todo próprio em relação ao cordel brasileiro e são muitos os termos para denominá-lo, tais como "folheto de feira", "folheto popular", "literatura de cordel", "literatura popular em versos", "romanceiro popular do Nordeste", dentre outros tantos. Não é objetivo deste artigo fazer um exercício de genealogia da emergência de cada um deles e da sua própria historicidade. O termo "folhetos em versos", utilizado por Francisco das Chagas Batista no seu estudo sobre os poetas de sua época e que foi contemporâneo aos autores de $O$ pavão misterioso será utilizado relacionado à materialidade do formato. Em relação ao gênero literário se fará uso do termo cordel brasileiro ou simplesmente cordel. A respeito ver: BATISTA, Francisco das Chagas. Cantadores e poetas populares. Parahyba: F. C. Baptista Irmão, 1929, p. 113; LUCIANO, Aderaldo. História crítica do cordel brasileiro. Rio de Janeiro: Edições Adaga; São Paulo: Luzeiro, 2012; SILVA, Gonçalo Ferreira da Silva. Dicionário Brasileiro de Literatura de Cordel. Rio de Janeiro: ABLC, 2005.
} 
identifica a autoria e se limita a afirmar ser "[...] "O pavão misterioso" sem autor conhecido[...]" (PROENÇA, 1942, p. 164).

Se há referências na oralidade, mas não comprovados por documentos, de que o texto poético fora publicado quase duas décadas antes do conteúdo ser registrado pelo estudioso citado acima, o certo é que o texto poético rapidamente ganhará reedições. A mais antiga das que se conhece tem exatamente 32 páginas, o principal padrão de paginação dos romances em versos, e se atribui a José Camelo a autoria, mesmo não tendo qualquer referência ao autor na capa7.

Por sua vez há fortes indicações de que foi João Melchíades Ferreira da Silva, de fato, o primeiro poeta a publicá-lo em folheto ${ }^{8}$. No entanto a materialização em impresso foi precedida por uma composição anterior - não escrita, mas forjada na mente e decorada para ser declamada, a quem se atribui ser mesmo de José Camelo de Melo Resende. ${ }^{9}$ Esta

\footnotetext{
${ }^{7}$ A edição pertence ao acervo da Fundação Casa de Rui Barbosa e foi editada por João Martins de Athayde, em Recife, nos anos de 1940. Se sabe que é do período pelo preço estampado nela que é de $\$ 3,00$ (três cruzeiros), o padrão monetário que passou a vigorar no Brasil em 1942. Por sua vez, João Martins de Athayde saiu do ramo em 1949. Daí se deduzir que a edição foi publicada neste interim de tempo. Ver: CAMELO, José. O pavão misterioso. Recife: [s.n.], [19- ]. 32 p.

${ }^{8}$ O poeta e cantador João Melchíades Ferreira da Silva (Bananeiras/PB, 1869 - João Pessoa/PB, 1933), que se autodenominava de "o Cantor da Borborema", consta entre os primeiros autores a publicar algumas das suas "histórias" nos chamados folhetos de versos. Não se sabe ao certo de quando é o primeiro, mas alguns dos seus poemas são editados pelos irmãos Francisco das Chagas e Pedro Batista (os pioneiros neste tipo de publicação na Paraíba) desde meados da segunda metade da década de 1910. No acervo Literatura Popular em Verso, da Fundação Casa de Rui Barbosa, o seu folheto datado mais antigo é de 1918 e a biografia indica que começou a publicar folhetos regularmente a partir de 1914. Uma importante referência sobre ele é dada pelo poeta, livreiro e editor Francisco das Chagas Batista, que o retrata no seu livro sobre os cantadores e poetas populares da época. Além de constar como autor da primeira edição do controverso O pavão misterioso, também escreveu outros clássicos do gênero. Ruth Terra, estudiosa de referência para o período inicial do cordel brasileiro, identificou 36 poemas como de autoria de Melchíades, a exemplo da História do valente sertanejo Zé Garcia; História de Juvenal e Leopoldina; História de Cazuza Sátyro -o matador de onça; O combate de José Colatino com a carranca do Piauí; Roldão no leão de ouro, dentre outros. A respeito da vida e obra do poeta, ver: BATISTA, Francisco das Chagas. Cantadores e poetas populares. Parahyba: F. C. Baptista Irmão, 1929, pp. 176-194; TERRA, Ruth Brito Lemos. Memória de lutas: literatura de folhetos do Nordeste (1893 a 1930). São Paulo: Global Editora, 1983, pp.51-54. Sobre o seu primeiro folheto datado, ver: SILVA, João Melchiades Ferreira da. A victoria dos alliados: a derrota da Allemanha e a influenza hespanhola. Paraíba: Popular Ed, 1918. 16 p. Disponível em: SOPHIA Biblioteca. João Melchíades. 〈http://acervos.casaruibarbosa.gov.br/>. Acesso em: 20 abr. 2021.

${ }^{9}$ A biografia de José Camelo de Melo Resende (Pilõezinhos/PB, 1885 - Rio Tinto/PB, 1964) é bastante problemática e pouco precisa por ter poucos dados documentados. O que se sabe é que ele era um irrequieto poeta, cantador e autor de folhetos, também considerado um dos grandes romancistas do gênero e autor de grandes clássicos, a exemplo do próprio $O$ pavão misterioso, a quem se atribui ser o criador de toda a trama fantástica do enredo poético. No Dicionário Biobibliográfico de Repentista e Poetas de Bancada, da autoria de Átila Almeida e José Alves Sobrinho, há informações a respeito dele que até hoje nunca foram comprovadas com uma maior precisão, como a de que viveu um tempo como foragido da justiça no Rio Grande do Norte, período em que a sua obra prima foi publicada por José Melchíades que estampou o próprio nome como autor. A respeito do poeta ver: ALMEIDA Átila; SOBRINHO, José Alves. Dicionário Biobibliográfico de Repentistas e Poetas de Bancada. Campina Grande: Centro de Ciências e Tecnologia;
} 
é a matriz utilizada por Melchíades, que a recriou em um texto mais enxuto e compôs a sua versão impressa, publicada na década de 1920, mas sem data precisa ou qualquer comprovação documental.

Também há evidências na oralidade - mas não comprovada em documentação escrita - que a obra também circulou em impressos com a autoria estampada na capa de um outro parceiro de cantoria dos dois poetas já citados10. Romano Elias da Paz ${ }^{11}$, ao que parece, não só cantava o poema como uma obra feita ${ }^{12}$ do repertório comum aos parceiros de cantoria (mesmo sabendo não ser da sua autoria), mas também vendia o folheto em suas apresentações pelo Nordeste ${ }^{13}$.

Um resumo de toda essa controvertida identificação de autoria pode ser lido no folheto Pedrinho e Julinha, da autoria de José Camelo de Melo Resende (2005), que foi editado na Coleção Cordéis Raríssimos da Academia Brasileira da Literatura de cordel em julho de 2005. Nele há um pequeno texto explicativo sobre o original da obra ser mesmo o de José Camelo, mas que acabou por ser publicado em um texto adaptado por João Melchíades. Ao falar sobre José Camelo o poeta e pesquisador Arievaldo Viana (2005), o autor do referido texto, destaca que:

João Pessoa: Editora Universitária, 1978. p. 235-237; ALMEIDA Átila; SOBRINHO, José Alves. Romanceiro Popular Nordestino. Marcos e Vantagens. Campina Grande: UFPB; URNe, 1981. p. 182.

${ }^{10}$ No Dicionário biobibliográfico de repentistas e poetas de bancada os autores afirmam que foi Romano Elias da Paz quem forneceu a João Melchíades a cópia manuscrita do poema. Ver: ALMEIDA Átila; SOBRINHO, José Alves. Dicionário Biobibliográfico de Repentistas e Poetas de Bancada. Campina Grande: Centro de Ciências e Tecnologia; João Pessoa: Editora Universitária, 1978. p. 212.

${ }^{11}$ Romano Elias da Paz (Mamanguape/PB, 1903 - Caiçara/PB, 1981), cantador paraibano que foi parceiro de cantoria de José Camelo e de João Melchíades, além de folheteiro nômade e poeta de bancada, escreveu mais de uma centena de títulos de cordéis. A respeito do poeta ver: BATISTA, op. cit., 1929, pp. 221-241; ROMANO Elias da Paz. Disponível em: <https://www.paraibacriativa.com.br/artista/romano-eliasda-paz/>. Acesso em: 20 abril. 2021. Sobre a obra do autor há poucas indicações e o acervo da Fundação Casa de Rui Barbosa dispõe de apenas três título, a saber: PAZ, Romano Elias da. A convivencia do Joazeiro e a formalidade do padre Cicero. Guarabira (PB, BR): Typ. e Livraria Pedro Baptista, 1923. 16 p.; PAZ, Romano Elias da. Heroísmo, amor de infância, Paulino e Helena. [S. l.]: [s.n.], [s.d.]. 32 p.; PAZ, Romano Elias da. Peleja de Romano Elias com Azulão. Guarabira: Tip. Pontes, s.d. 23 p. A respeito ver: SOPHIA Biblioteca. Romano Elias da Paz. Disponíveis em: < http://acervos.casaruibarbosa.gov.br/>. Acesso: em 20 abr. 2021.

${ }^{12} \mathrm{O}$ termo é indicativo de composições que os cantadores tinham decoradas no seu repertório para ser apresentadas ao seu público de ouvintes em certo momento da cantoria. Este era o caso de $O$ Pavão Misterioso, enredo originalmente composto por José Camelo com esta finalidade e que certamente fazia muito sucesso em suas apresentações. Basta ver que a obra cantada foi depois publicada pelos dois cantadores já citados, possivelmente em uma versão adaptada daquela originalmente criada por José Camelo.

${ }^{13}$ Em depoimento tomado pelo pesquisador José Paulo Ribeiro, na cidade de Caiçara-PB, a uma nora do cantador Romano Elias da Paz, ela diz ter visto o folheto do pavão com o nome deste encorpado na capa. No entanto, o documento se perdeu e nunca foi localizado. Este relato do fato foi feito pelo próprio José Paulo Ribeiro, em áudio enviado ao autor deste artigo no dia 25 de abril de 2021. 
[...] sua obra mais famosa, "Romance do Pavão Mysteriozo" tem uma história controversa. Segundo os pesquisadores, esse folheto foi escrito originalmente com 40 páginas em 1923, para ser cantado em apresentações. João Melchíades Ferreira, ajudado por Romano Elias da Paz, obteve uma cópia do mesmo e o reescreveu com apenas 32 páginas, publicando como obra de sua autoria. Consta que José Camelo, desgostoso com o sucesso obtido por Melchíades, findou rasgando os seus originais. [...]. ${ }^{14}$

Vê-se claramente que há uma questão relevante quanto à autoria da obra. Esta é bastante problemática porque não está definida pelos direitos autorais a partir da criação (aquele que se baseia na originalidade da composição). Por sua vez, o enredo se apresenta em um novo texto - não mais aquele guardado na memória e expressado pela voz de José Camelo ao ser cantado -, recriação transposta da oralidade para a escrita. O nó da querela é o fato de que a nova autoria, a de José Melchíades, faz com que o texto recriado se torne a matriz (já que o original não veio à tona e foi pretensamente rasgado pelo verdadeiro criador).

Se, de direito, o criativo poeta (de rima rica e métrica perfeita) José Camelo de Melo Resende é o autor que criou e idealizou todo o enredo - que por toda a vida teve a consciência autoral sobre a sua produção poética, chegando a vender os direitos de editoração e publicação para outros (e por mais de uma vez) -, também parece certo de que a versão de João Melchíades - o autor que refez o romance e o publicou em folheto de 32 páginas - se tornou a mais conhecida. Sendo assim, os dois dividem a autoria sobre a obra que continua a ser reproduzida continuamente até hoje.

Mas nada em torno da autoria de $O$ pavão misterioso parece ser tão simples assim. O poeta José Camelo, por exemplo, nem sempre foi lembrado pelos estudiosos como um dos maiores nomes do romance de cordel. A vida desregrada, um misto de poeta boêmio e andarilho mercador de versos e cantador de viola, também contribuiu para que a sua obra fosse subtraída em sua autoria. O que levou a ter profundo desgosto ao ponto de rasgar os originais.

Segundo familiares, e conforme indicado no próprio batistério - localizado pelo pesquisador paraibano José Paulo Ribeiro ${ }^{15}$, grande estudioso da obra de José Camelo,

\footnotetext{
${ }^{14}$ Originalmente o texto de Arievaldo Viana foi publicado na página da Câmara Brasileira de Jovens Escritores na internet. Ver: VIANA, Arievaldo. José Camelo de Melo Rezende. Disponível em: <http://www.camarabrasileira.com.br/cordel15.htm>. Acesso em: 22 abr. 2021; CAMELO, José. Pedrinho e Julinha. Rio de Janeiro: Academia Brasileira de Literatura de Cordel, 2005. p. 4-6. Coleção Cordéis Raríssimos.

15 Em junho de 2013, por ocasião dos 90 anos do que é considerado a primeira edição do folheto, o pesquisador José Paulo Ribeiro abriu o seu acervo particular de obras e documentos raros para ser conferido
} 
ele veio ao mundo na localidade de Pedro Vieira, em Pilõezinhos. Já o bom versejador surge no início dos anos de 1920 na cidade de Guarabira, a qual pertencia o então distrito. Ali tem início a sua jornada de autor de romances e é lá onde publica os seus primeiros poemas em cordel, a exemplo de A grande inundação de 1924, em Guarabira ${ }^{16}$. Entre idas e vindas passou um curto período no Rio Grande do Norte, do qual pouco se sabe. É dessa época a controversa questão da autoria de $O$ Romance do Pavão Misterioso - a quem se atribui ser o poeta o primeiro a versá-la, mas que acabou sendo publicada em folheto $^{17}$, por João Melchíades Ferreira da Silva.

É importante dizer que são muitos os títulos de José Camelo que merecem destaque, não só $O$ pavão misterioso. Das suas obras referenciais - e outras não tão conhecidas - aqui citamos: A afilhada do padre Cícero (s.d.); A corrução é assim (s.d.); A índia fidalga (s.d.); A neta de Cancão de Fogo (s.d.); A verdadeira história de Joãozinho e Mariquinha (s.d.); As grandes aventuras de Armando e Rosa conhecidos por "Côco Verde" e "Melancia" (1964); Entre o amor e a espada (1948); História de três cavalos encantados e três irmãos camponeses (1979); História do Conde Gaston Marcel e a Duqueza Estelita (s.d.); O valor da mulher (1952); Os martírios de Lelena (s.d.), dentre outras tantas que estão depositadas nos mais importantes acervos do país ${ }^{18}$.

Também deve-se ressaltar que suas obras foram editadas e publicadas nos grandes centros de produção cordeliana de então. Em Guarabira é possível encontrarmos os seus folhetos compostos na Livraria e Tipografia Lima, a exemplo de A peleja de Chica Paculú com o cego Victurino (s.d.); além dos editados por Manoel T. Baraúna, como a História

na exposição "Um olhar contemporâneo do Pavão Misterioso”. O evento aconteceu ao longo do mês no SESC Guarabira. A respeito, ver: SESC homenageia o cordel com a exposição "Um olhar contemporâneo do Pavão Misterioso": A respeito ver: PBAGORA. Disponível em: <https://www.pbagora.com.br/noticia/cultura/sesc-homenageia-o-cordel-com-exposicao-um-olharcontemporaneo-do-pavao-misterioso/> . Acesso em: 25 abr. 2021.

${ }^{16}$ No Dicionário Biobibliográfico de Repentistas e Poetas de Bancada há referência a esse que é um dos seus primeiros folhetos publicados. Ver: ALMEIDA Átila; SOBRINHO, José Alves. Dicionário Biobibliográfico de Repentistas e Poetas de Bancada. Campina Grande: Centro de Ciências e Tecnologia; João Pessoa: Editora Universitária, 1978. p. 236.

${ }^{17}$ Os indícios mais aproximados a respeito da primeira edição é de que seja dos anos em que José Camelo de Melo Resende passou uma temporada no Rio Grande do Norte, possivelmente no início dos anos de 1930. O ano de 1923, que sempre aparece como aquele em que a obra veio à luz, provavelmente se refere à composição e a apresentação dela pelo autor nas cantorias das quais participava. Ver: ALMEIDA; SOBRINHO, op. cit., p. 235.

${ }^{18}$ Dentre as instituições que dispõem de algumas das obras relacionadas, destaca-se a Biblioteca de Obras Raras Átila de Almeida (BORAA), da Universidade Estadual de Campina Grande; o Centro Nacional do Folclore e Cultura Popular (CNFCP), localizado no Rio de Janeiro e a Coleção Literatura Popular em Verso da Fundação Casa de Rui Barbosa (FCRB), também na cidade do Rio de Janeiro. 
do Conde Gaston Marcel (s.d.) e pela Tipografia Pontes, História do poeta Ramos Patrício e Zulmira Feitosa: sofrimentos, amor e aventura (1979). Em Campina Grande há os editados por Sebastião José do Nascimento, como a Duqueza Estelita (s.d.), A verdadeira história de Joãozinho e Mariquinha (s.d.), História do poeta Ramos Patrício e Zulmira Feitosa (s.d.) e os editados pela A Estrella da Poesia, de Manoel Camilo dos Santos, a exemplo de $O$ índio Leão (1958). Em Recife foi editado por João Martins de Athayde, por exemplo, Entre o amor e a espada (1948) e o próprio O pavão misterioso (s.d.); também por João José da Silva, como História do bom pai e o mau filho (s.d.) e ainda pela Casa das Crianças de Olinda, a exemplo do título A corrução é assim (s.d.). Em São Paulo pela Editora Prelúdio, O pavão misterioso em quadrinhos (s.d.) e pela Luzeiro Editora, O pavão misterioso (1976), História de três cavalos encantados e três irmãos camponeses (1979) Em Fortaleza por Joaquim Batista de Sena, História da princêsa Adalgisa e o pintor Haroldo de Vilanaz (s.d.), O pavão misterioso (s.d.) e, ainda no Ceará, encontramos os seus folhetos editados em Juazeiro do Norte por José Bernardo da Silva, Entre o amor e a espada (1960), Pedrinho e Julinha (1959) e por Manoel Caboclo e Silva, Estória de Aprígio Coutinho e Neusa (1975), A princesa Adalgisa e o pintor Haroldo de Vilanaz (1975).

Voltado à publicação por João Melchíades de um enredo (e mesmo versos completos) que advinha do gênio imaginário de um outro autor, o engenhoso romancista Zé Camelo, é necessário ressaltar que o novo texto é ao mesmo tempo o ponto de junção entre eles e o motivo de embate entre os editores a partir de um pretenso direito sobre a obra, dado por ou por outro. A distinção na autoria e as diversas edições de um dos clássicos do gênero cordeliano permitiram muitas versões, na sua grande maioria se valendo do texto publicado por João Melchíades. Depois que este faleceu a família também venderia os direitos sobre a obra para Manoel Camilo dos Santos, que passa a publicá-la em Guarabira, em meados da década de 1950.

Assim, se José Camelo é o criador da obra, cabe a Melchíades recriá-la em um novo texto que se torna a referência para as demais edições. Inclusive as que se fizeram com a autoria atribuída a José Camelo e a que ele próprio autorizou a ser publicada por Joaquim Batista de Sena, com a ressalva explicativa das primeiras estrofes e do acróstico final. 


\section{Recriação da materialidade em diferentes edições}

A movência da obra - recriação estabelecida a partir da oralidade em que foi produzida por José Camelo até o texto recriado e impresso por Melchíades - repercute em novos usos e na própria materialidade. Assim, através da análise da materialidade gráfica de algumas das muitas edições de $O$ pavão misterioso, o termo genérico que encontramos para nomear o texto matriz de Melchíades e de onde se originou as diversas edições, podemos entender o processo de contínua reiteração da obra.

Através da análise dos usos diferenciados e materialidades diversas dos textos produzidos a partir do enredo que os gerou, o propósito aqui não é o de fazer um inventário exaustivo, mapeando uma a uma as muitas edições, mas estabelecer apontamentos necessários a quem queira entender o complexo problema da sua autoria e a história das edições dentro do circuito editorial por onde percorreu a obra e seus desdobramentos como tal em outros textos. Vamos nos utilizar, para tanto, de alguns dos acervos mais completos (Acervo José Paulo Ribeiro/Guarabira-PB; Biblioteca de Obras Raras Átila Almeida/Campina Grande-PB; Centro Nacional do Folclore e Cultura Popular/Rio de Janeiro-RJ; Fundação Casa de Rui Barbosa/Rio de Janeiro-RJ) e para perceber as mudanças dos sentidos construídos na materialidade e nas leituras que se faz delas.

A partir do grande número de edições - estimadas em mais de cinquenta - ainda não há consenso e são muitas as impressões que os estudiosos têm a respeito do texto, materialidade e autoria de $O$ Pavão Misterioso. A mais antiga referência provavelmente é aquela, já citada, de Manoel Cavalcante Proença (1942), que o trata como obra anônima, mas bastante apreciada, que circula nas ribeiras do São Francisco.

No livro de Francisco das Chagas Batista (1929), editor que conheceu José Camelo e que publicou algumas das obras de Melchíades, não há referência a qualquer título de Melchíades, muito menos ao tão falado O pavão misterioso. Por sua vez, nele o suposto autor, José Camelo, nem mesmo é apresentado como um dos "Cantadores e poetas populares" (BATISTA, 1929). Uma hipótese é a de que mesmo convivendo ao círculo de poetas próximos a este, a exemplo do próprio Melchíades, e de residir um bom tempo em Guarabira, cidade onde Pedro Batista - o irmão de Chagas Batista - era livreiro e editor, José Camelo teria uma tumultuada e inconstante vida particular que o impediu (mas não se sabe ao certo o porquê) de ser retratado como um dos poeta de referência 
para aquele editor. Outra hipótese é a de que ao emigrar para o Rio Grande do Norte, exatamente no período em que Melchíades passa a editar a obra e vendê-la como de sua autoria, fica meio que esquecido em seu exílio voluntário e por motivo também ainda não totalmente esclarecido ${ }^{19}$.

A versão mais antiga que se conhece da obra não está datada, mas se presume pelo preço estampado na capa, $\$: 3,00$ cruzeiros, que é dos anos de 1940. Publicada em Recife pela Casa Ataíde, editora de João Martins de Athayde, o documento pertence ao acervo da Fundação Casa de Rui Barbosa, constando a autoria como de José Camelo de Melo Resende. ${ }^{20}$ Possivelmente é essa a que Cavalcante Proença se deparou nas barrancas do S. Francisco, circulando entre os ribeirinhos. A autoria atribuída a José Camelo é provável, mesmo não constando na capa, pois o autor tinha negócios com Athayde que publicou algumas das suas obras, se valendo da condição de editor proprietário e a partir desse artifício não fazendo qualquer referência à autoria do poeta.

Em 1949 todo o estoque da Casa Ataíde e os direitos sobre as obras que detinha o editor João Martins de Athayde é vendido para o também editor José Bernardo da Silva, proprietário da Tipografia São Francisco, em Juazeiro do Norte, que passa, assim, a ser legalmente o proprietário de $O$ pavão Misterioso. A transação foi realizada nas formas da lei em cartório do Recife, conforme atesta a documentação apresentada na pesquisa de Rosilene Alves de Melo: “após muita negociação, a transação foi finalmente concluída e registrada no Cartório Gonzaga Macedo, em Recife, no dia 08 de julho de 1949. Em 1954 foi registrado novamente, desta vez no Cartório Machado, em Juazeiro do Norte” (MELO, 2010, p. 94).

Entretanto, o principal registro que se tem documentado em cartório a respeito dos direitos de José Camelo sobre O Pavão Misterioso é o registro do recibo da Compra de Autoria por Cr. $\$ 10.000,00$, juntamente com outros títulos de sua lavra, efetivado no dia 22 de maio de 1954 no cartório em Guarabira (PB) no ano de 1954 a favor do poeta e

\footnotetext{
${ }^{19}$ Se cogita três hipóteses da sua ida ao Rio Grande do Norte, seja por falsificação de rótulos de bebidas, seja por ter recebido cédulas falsas de um editor de Recife ou, ainda, por uma questão de cunho pessoal, relativa ao coração do sonhador poeta. Esta última levantada pelo pesquisador José Paulo Ribeiro, em troca de mensagens com o autor do artigo A respeito da primeira, ver: SANTOS, Idelette Muzart-Fonseca. Memória das Vozes: cantoria, romanceiro \& cordel. Salvador: Fundação Cultural do Estado da Bahia, 2006. p. 68-70. Sobre a segunda versão, ver: VIANA, Arievaldo. A maior polêmica do cordel. Disponível em: <http://acordacordel.blogspot.com/2012/02/maior-polemica-do-cordel.html >. Acesso em: 26 abr. 2021.

20 No folheto não há indicação de editor e nem datação. Ver: CAMELO, José. O pavão misterioso. Recife: [s.n.], [19- ]. 32 p. - FCRB.
} 
editor Joaquim Batista de Sena. O pesquisador José Paulo Ribeiro é quem mantém, em seu acervo particular, uma cópia do recibo que descreve os pormenores do negócio, conforme se vê abaixo:

Compra de autoria dos seguintes folhetos: "Evangelista e Creusa" ou O Pavão Misterioso". "Pedrinho e Julinha" conhecido por "Pedro Rafael". Entre o Amor e a Espada" conhecido por Côco Verde e Melancia". "Esmeraldina e Otaciana" conhecida como Neta de Cancão de Fogo". O primeiro folheto "Pavão Misterioso" é impresso com 40 páginas, e, os demais, contêm 32 páginas. Como autor não poderei jamais imprimi-los, feita que foi a venda da autoria. Podendo o Sr. Joaquim Batista de Sena, chamar à responsabilidade a quem quer que os imprima sem a sua prévia autorização. Como garantia da fazenda da autoria passo-lhe o presente recibo, afim de resguardar todos os seus direitos de comprador. ${ }^{21}$

Assim, na ocasião, os direitos sobre algumas das principais obras do poeta são repassados para o editor Joaquim Batista de Sena, época em que José Camelo já se encontrava instalado com a família na cidade paraibana de Rio Tinto e onde veio a falecer dez anos depois. E o mais curioso, verdadeiro achado, a indicação de que há um texto maior, com mais estrofes e com 40 páginas. Esta seria a versão de José Camelo (s.d.), plagiada ou recriada por João Melchíades (s.d.) conforme o ponto de vista que se queira dar ao repertório que foi comum entre os dois.

O certo é que o folheto foi publicado pelo editor e existe uma cópia dele na Biblioteca de Obras Raras Átila Almeida ${ }^{22}$. Mas o próprio Joaquim Batista de Sena (s.d.) só o publicou uma única vez, provavelmente pelo fato de a "versão original" não ser bem recebida pelo público e, assim, voltou a publicar o texto já conhecido, o de João Melchíades (s.d.). Essa mesma opinião é reforçada nas palavras abalizadas do poeta Expedito Sebastião da Silva, o gráfico responsável pela editoração dos folhetos na Tipografia São Francisco, de José Bernardo da Silva em depoimento ao editor e poeta Abraão Batista, quando diz que a versão de 40 páginas, a de José Camelo (s.d.), não obteve sucesso junto ao "gosto popular":

\footnotetext{
${ }^{21}$ Uma cópia do recibo de compra de autoria foi solicitada pelo pesquisador José Paulo Ribeiro ao Cartório José Floripes Miranda e Sá - $2^{\circ}$ Tabelião e Oficial de Registros de Títulos e Documentos, da cidade de Guarabira, na Paraíba, em 22 de junho de 1984. Atualmente ela encontra-se depositada em seu acervo particular, ao qual tivemos autorização de acesso em 24 de maio de 2021.

${ }^{22}$ Mesmo que não esteja datado é possível pensar que foi publicado no mesmo ano em que foi realizada a compra, por Batista de Sena, dos direitos sobre a obra. Ver: CAMELO, José. O pavão misterioso. [S. 1.]: Ed. Proprietário Joaquim Batista de Sena, [19- ]. 40 p.
} 
Segundo Expedito Sebastião da Silva, poeta e gráfico da antiga editora de José Bernardo, João Melquíades (sic.) plagiou o Pavão Misterioso, o original de José Camelo de Melo. O plágio vendeu melhor que o original. A gráfica José Bernardo seguiu o gosto popular. José Camelo, desgostoso, rasgou o seu original que perdera a concorrência. ${ }^{23}$

Um novo movimento nos direitos sobre $O$ pavão misterioso acontece no início da década de 1970, coincidindo com a grande crise (que se arrastava desde o final dos anos de 1950) na produção e venda da literatura de $\operatorname{cordel}^{24}$. O que faz com Joaquim Batista de Sena transfira os direitos da obra para a Editora Prelúdio, de São Paulo, a mesma cuja os proprietários já a publicou, mas sem autorização, desde os tempos da Tipografia Souza (s.d.), empresa do pai dos proprietários e que a antecedeu no ramo de impressos. Na cópia do documento de Autorização de Publicação, também em poder de José Paulo Ribeiro, diz que “[...] O preço de tal cessão é de 200,00 (duzentos cruzeiros), pagos e quitados nesta data. [...] São Paulo, $1^{\circ}$ de outubro de 1970"25.

Do que foi dito se deduz que José Camelo vendeu os seus direitos sobre a obra duas ou mais vezes. Primeiro para João Martins de Athayde, depois para Joaquim Batista de Sena que, por sua vez, revendeu os direitos sobre a obra para a Editora Prelúdio, de Arlindo Pinto de Souza, que publicaria uma versão em quadrinhos. Este, depois, mudaria a razão social da empresa para Luzeiro Editora, ainda no início da década de 1970, e publicaria outras edições de $O$ pavão misterioso (s.d.; 1976; 1980) ${ }^{26}$.

Da outra parte, a da família de João Melchíades, há indicações de que vendeu os direitos de publicação de seus títulos para Manoel Camilo dos Santos, dentre estes $O$

\footnotetext{
${ }^{23}$ Esse depoimento foi publicado em uma reedição de 1990, que compunha a Biblioteca Nacional do Cordel, parte de uma série de publicações organizada pelo poeta e xilógrafo Abraão Batista. Ver: BATISTA, Abraão. História do pavão misterioso. Juazeiro do Norte: [s.n.], 1990, p. 32. (Biblioteca Nacional do Cordel).

${ }^{24} \mathrm{~A}$ denominação é estabelecida em definitivo a partir do seu uso nos estudos institucionais e acadêmicos a respeito do assunto, iniciados em meados da década de 1950. A partir dos anos de 1970 estes se avolumam, ao ponto de quase sobrepujar todas as demais denominações até então usuais. Ver: ARAÚJO, Alceu Maynard. Literatura de cordel. In: Vida Rotária, São Paulo, n.65, Ano VII, out. 1955; AZEVEDO, Carlos Alberto. O heroico e o messiânico na literatura de cordel: ensaio de sociologia da literatura. Recife: Edicordel, 1972; BIDERMAN, Sol. Messianismo e escatologia na literatura de cordel. 1970. Tese (Doutorado). Universidade de São Paulo, Faculdade de Filosofia Ciências e Letras, São Paulo, 1970; CANTEL, Raymond. Temas da atualidade na literatura de cordel. São Paulo: USPIECA, 1972.

${ }^{25} \mathrm{O}$ documento encontra-se depositado no acervo particular de José Paulo Ribeiro, em Guarabira, na Paraíba, ao qual tivemos autorização de acesso em 24 de maio de 2021.

${ }^{26}$ As editoras Gráfica Souza, Prelúdio e Luzeiro, da família de Arlindo Pinto de Souza e que se sucederam nesta ordem, publicaram $O$ pavão em diferentes edições, mesmo antes da compra dos direitos sobre a obra. A respeito, ver: RESENDE, José Camelo de. O pavão misterioso. São Paulo: Luzeiro, 1976. 31 p. (Coleção Luzeiro); RESENDE, José Camelo de. O pavão misterioso. São Paulo: Luzeiro, 1980. 32 p.; RESENDE, José Camelo de. O pavão misterioso em quadrinhos. São Paulo: Prelúdio, s.d. 38 p.; O PAVÃO misterioso. São Paulo: Ed. Graf. Souza, 1959. 32 p.
} 
pavão misterioso. No livro Na memória da tradição: fontes de informação em literatura de cordel há um registro bastante pertinentes a esse respeito:

[...] Após a morte de João Melchíades, sua esposa Senhorinha e seus filhos venderam os direitos de publicação ao poeta e Cantador Manuel Camilo dos Santos, que passou a editar os folhetos de Melchíades. Entretanto, naquela ocasião, os cordéis já eram publicados por João Martins de Athayde e, posteriormente, por José Bernardo da Silva, principalmente "O romance do pavão misterioso" (ALBUQUERQUE, 2016, pp. 248-249).

No entanto, não localizamos qualquer documento que aponte o ano da venda para Manuel Camilo, mas o certo é que este passou a publicar o folheto como editor proprietário e pondo o nome de Melchíades na capa já em meados da década de 1950. No acervo do Centro Nacional de Folclore e Cultura Popular (CNFCP), por exemplo, há uma edição do final desta década. ${ }^{27}$ Por sua vez na quarta capa do folheto Combate de José Colatino com a carranca do Piauí, obra de João Melchíades (1955) editada por ele em Campina Grande (PB) com data de 19 de novembro de 1955, se pode ler uma chamada que faz ao seu leitor, reiterando a necessidade de atenção para sua propriedade sobre títulos daquele poeta:

[...]Sendo que: O Pavão Misterioso, O Valente Zé Garcia, A Cigana Esmeralda e seu Testamento, Juvenal e Leopoldina, Roldão no Leão de Ouro, Cazuza Sátiro O Matador de Onças, O Sertanejo Orgulhoso e os seus Filhos na Praça, José Colatino e a carranca do Piauí, As Quatro Órfãs de Portugal e todas as mais de autoria de João Melchíades Ferreira da Silva. As quais, para a garantia dos direitos de minha propriedade, acham-se escrituradas e registradas na Biblioteca Nacional do Rio de Janeiro. ${ }^{28}$

Na principal linha que se desenrolou as edições, a que se segue a João Martins de Athayde, o editor José Bernardo da Silva publica em 10 de janeiro de 1949, na Tipografia São Francisco em Juazeiro do Norte, a História do pavão misterioso. Creuza e Evangelista (1949). Utilizando-se do mesmo artifício de Athayde, o de ser o editor proprietário, mas o folheto não tem qualquer atribuição de autoria e a marca de propriedade somente nos remete ao editor. No entanto, a versão é a de 141 estrofes em 32 páginas, a de Melchíades.

\footnotetext{
27 Ver: RESENDE, José Camelo de. Romance do pavão misterioso. Campina Grande: Ed. Proprietário Manoel Camilo dos Santos: A Estrella da Poesia, 1959.

${ }^{28}$ Importante ressaltar que não foi localizado o documento de registro da transação em cartório, mas tão somente essa referência ao registro da obra literária na Biblioteca Nacional. Ver: SILVA, João Melchídes Ferreira da. Combate de José Colatino com a carranca do Piauí. Campina Grande: Tipografia e Folhetaria Santos, 1955.
} 
É sabido que o editor de Juazeiro do Norte refez inúmeras vezes as capas, o título da obra e ao seu bel prazer dispunha, ou não, a autoria do pavão. Por exemplo, o título Romance do pavão misterioso: história completa (1961) vingou no início da década, com sucessivas edições em 1961, 1963 e $1965,{ }^{29}$ mas todos com a autoria agora atribuída a João Melchíades Ferreira da Silva. Após a morte do editor, em 1972, os herdeiros continuaram a publicar e a recriar títulos - e respectivas capas -, de acordo com os interesses comerciais vigentes e aos nomes fantasia que passaram a adotar, a exemplo de Filhas de José Bernardo da Silva, um dos mais usados. ${ }^{30}$ Depois com a venda da gráfica e de todo o seu acervo ao Governo do Estado, em 1982 - e que desde 1980 fora renomeada Lira Nordestina -, O pavão misterioso passa a ser também de propriedade estatal (MELO, 2010, p. 166) ${ }^{31}$.

\section{Movência, ressignificações e usos de $O$ pavão misterioso}

Já passados quase 100 anos desde que a obra criada por José Camelo veio à tona, ela cada vez mais permanece viva no imaginário cultural brasileiro. Quanto ao texto recriado por João Melchíades é o que se fixa, pois ao ser publicado serve de inspiração para outras tramas que se forjam a partir dele. Como enredo poético que se estabelece é ele que enseja o movimento em direção a outras linguagens artísticas e adaptações as mais diversas. No folheto intitulado O filho de Evangelista do pavão misterioso (s.d.), da autoria de Manoel Apolinário Pereira ${ }^{32}$, temos um exemplo do que foi dito acima. O texto

\footnotetext{
${ }^{29}$ A cada nova edição é possível notar pequenas alterações na materialidade, principalmente na quarta capa reservada à publicidade. Ver: SILVA, João Melchiades Ferreira da. Romance do pavão misterioso: história completa. Juazeiro do Norte: Tip. São Francisco; José Bernardo da Silva, 1961.; SILVA, João Melchiades Ferreira da. Romance do pavão misterioso: história completa. Juazeiro do Norte: Tip. São Francisco; José Bernardo da Silva, 1963.; SILVA, João Melchiades Ferreira da. Romance do pavão misterioso: história completa. Juazeiro do Norte: Tip. São Francisco; José Bernardo da Silva, 1965.

${ }^{30}$ Logo depois do falecimento de José Bernardo da Silva, em 1972, a família continuou a publicar do mesmo modo anterior, com o nome do editor. Somente depois é que passou a utilizar outras denominações para nomear a editora. Ver: SILVA, João Melchiades Ferreira da. Romance do pavão misterioso. Ilustrações de Stênio. Juazeiro do Norte: José Bernardo da Silva, 1975.; SILVA, João Melchiades Ferreira da. Romance do pavão misterioso. Ilustrações de Stênio. Juazeiro do Norte: Filhas de José Bernardo da Silva, [s.d.].; SILVA, João Melchiades Ferreira da. Romance do pavão mysterioso: história completa. Juazeiro do Norte: [s.n.], 1978.; SILVA, João Melchiades Ferreira da. Romance do pavão mysterioso: história completa. Juazeiro do Norte: José Bernardo da Silva, 1981.

${ }^{31}$ Sobre os folhetos já com a chancela da Lira Nordestina, ver: SILVA, João Melchiades Ferreira da. Romance do pavão misterioso: história completa. Juazeiro do Norte: Filhas de José Bernardo da Silva: Lira Nordestina, 1981.; SILVA, João Melchiades Ferreira da. Romance do pavão misterioso. Juazeiro do Norte: Lira Nordestina, 2006.

${ }^{32}$ Ver: PEREIRA, Manuel Apolinário. O filho de Evangelista do pavão misterioso. Recife: João José Silva, [s.d.].
} 
foi publicado por João José da Silva, em Recife. A data é indefinida, mas certamente antes da morte do autor, em 1955. Depois, na segunda metade da década de 1960, os direitos sobre a obra, e de todo o acervo da editora Luzeiro do Norte, de propriedade de João José da Silva, seria vendido para a Editora Luzeiro - que já publicava $O$ pavão Misterioso (s.d.) em São Paulo. Lá teria outra edição e é nela que se tem informações sobre a vida de Manoel Apolinário Pereira (PEREIRA, s.d., p. 2). Quanto à trama, logo no início o autor sugere continuidade - "Sabemos que Evangelista/Foi herói e teve glória/De esposar a linda Creusa,/Que todos têm em memória/Vamos ver do filho dele,/Qual será sua vitória" (PEREIRA, s.d., p. 3) - e os principais personagens de $O$ pavão misterioso seguem presentes. No entanto é um outro enredo, o que demonstra reiterações e movências a partir do texto matriz que o inspirou.

Ainda no campo do cordel fez relativo sucesso $O$ pavão misterioso em quadrinhos (s.d.), editado pela Prelúdio em São Paulo. O destaque, além do traço inconfundível do ilustrador Sérgio Lima, é que a edição tem 142 estrofes, pois acrescida de um acróstico ${ }^{33}$ final, sob o nome de José Camelo: Justiça só a de Deus/O juiz que já não erra/Senho que do céu pra terra/Entende os poderes seus...Como somos pigmeus/A ele não enxergamos/Mas contudo precisamos/Enaltecer sua luz/Lembrados que com Jesus/O Satanás afastamos". ${ }^{34}$ A Luzeiro (sucessora da Prelúdio), em parceria com a Editora Tupynanquim, de Fortaleza, ainda faria nova edição em quadrinhos, em 2010, com ilustrações de Klévisson Viana e recriações em toda a parte gráfica, paginação e balões de diálogos 35 .

Na segunda metade da década de 1970, período em que se observa uma retomada na produção e venda de cordel principalmente entre o público médio urbano de universitários e de imigrantes nordestinos em cidades como São Paulo, o poeta baiano Franklin Maxado aproveita o ensejo para lançar o folheto A volta do pavão misterioso (1976). ${ }^{36}$ Nele a tônica é a de falar sobre o fim que levou o "tal pavão", a partir da voz

\footnotetext{
${ }^{33} \mathrm{O}$ acróstico final é uma espécie de assinatura dos poetas de cordel para referendar a autoria e estratégia utilizada para evitar o uso indevido de suas criações. Inovação introduzida por Leandro Gomes de Barros, ainda hoje permanece como marca distintiva da autoria no gênero literário. Ver: LUCIANO, Aderaldo. História crítica do cordel brasileiro. Rio de Janeiro: Edições Adaga; São Paulo: Luzeiro, 2012, pp. 72-77. ${ }^{34}$ Muito embora a capa fosse colorida, o corpo do texto com ilustrações era todo em preto e branco. Ver: CAMELO, José. O pavão misterioso em quadrinhos. São Paulo: Prelúdio, s.d.

${ }^{35}$ Nesta edição as ilustrações são todas coloridas. Ver: CAMELO, José. O pavão misterioso - cordel em quadrinhos. São Paulo: Luzeiro; Fortaleza: Tupynanquim, 2010.

${ }^{36} \mathrm{Na}$ capa há uma ilustração em xilogravura do próprio autor. Ver: MAXADO, Franklin. A volta do pavão misterioso. São Paulo: [s.n.], 1976. 8 p.
} 
que é dada à ave, personagem que diz ter estado no Brasil e inspirado o autor, já então reconhecido amplamente como sendo criação de José Camelo: "Visitei José Camelo/Lhe contei aquela história/Que a rimou bem gostosa/Pegou merecida glória/Se ele ainda fosse vivo/Confirmava sua vitória" (MAXADO, 1976, p. 4).

Certamente que a recriação acima, a partir do texto matriz de $O$ pavão misterioso, foi elaborada sob a influência da mais conhecida das adaptações da obra para outra linguagem artística. A canção Pavão Mysterioso, que o cantor e compositor cearense Ednardo gravou no LP O Romance do pavão mysterioso $(1974)^{37}$, dois anos depois seria o tema de abertura da novela Saramandaia, veiculada pela Rede Globo. A recriação do tema faria a obra ainda mais conhecida e nos mais longínquos rincões do país. Na quarta capa do folheto de Franklin Maxado a letra da música está reproduzida em sua íntegra, demostrando o quanto a associação entre os textos, o do cordel e o da composição, intercambiava usos distintos ou diferenciados. Em outros trechos o autor faz referências ao compositor "Inspirou o moço Ednardo/Prá sua música letrar[...]" e à própria novela “[...] Ele já foi novela e música/Na tal da Saramandaia[...]” (MAXADO, 1976, p. 6). O resultado é o que poderíamos chamar de apropriações culturais do texto matriz, utilizando o sentido do termo conforme Roger Chartier (1990, p. 56).

Assim, a viagem de $O$ pavão misterioso vai sendo recriada. Sua literariedade movente é adaptada ao teatro, à televisão, à música. A imagética das capas, associada ao enredo fantástico, torna-se modelo para selos e cartões postais (a partir da arte gráfica de Jô Oliveira), ${ }^{38}$ dentre outras linguagens e expressões culturais. O mesmo enredo da versão de João Mechíades (s.d.) também chegou a ser lançado no formato de LP, no início dos anos de 1980, sendo que o texto é atribuído a José Camelo. No áudio, a obra é declamada na integra pelo jornalista e rádio ator Aldemar Paiva $(1983)^{39}$.

\footnotetext{
${ }^{37}$ A respeito de O Romance do Pavão Mysteriozo, ver: ENCICLOPÉDIA Itaú Cultural de Arte e Cultura Brasileiras. São Paulo: Itaú Cultural, 2021. Disponível em: <http://enciclopedia.itaucultural.org.br/obra70517/o-romance-do-pavao-mysteriozo〉. Acesso em: $26 \mathrm{de}$ Mai. 2021.

38 Ver: A ARTE e o folclore em selo. História de JÔ Oliveira. Disponível em: $<$ https://acervo.museudapessoa.org/pt/conteudo/historia/a-arte-e-o-folclore-em-selos 2910/colecao/www.museudapessoa.net. >. Acesso em: 06 mai. 2021.

${ }^{39} \mathrm{O}$ texto é interpretado por Ademar Paiva em sua íntegra, acompanhado por músicas incidentais da autoria de Djalma Coutinho e Fernando Borges e dividido em quatro faixas: 1 . O voo do pavão; 2. A viagem; 3. Evangelista e a condessa; 4. As bodas de Creusa. Ver: ADEMAR PAIVA. O pavão misterioso. Direção musical: Djalma Coutinho. São Paulo: FERMATA, 1983. Disco sonoro, 33 1/3rpm, estéreo, 12 pol.
} 
Mais recentemente, o enredo Cordel Branco e Encarnado (2012), da escola de samba carioca Acadêmicos do Salgueiro, faz uma série de referências ao universo do cordel. No trecho que diz "[...]sou cabra da peste/Oh minha fia, eu vim de longe pro Salgueiro/Em trovas, errantes, guardei/Rainhas e reis e até heróico bandoleiro/Na feira vi meu reinado que surgia/Qual folhetim, mais um cadim, vixe Maria!/Os doze do imperador/Que conquistou o romanceiro popular/ viagem de barca,/ A ave encantada/Amor que vence na lenda/Mistério pairando no ar[...]" a "ave encantada" é destacada em sua lenda de amor e mistério. ${ }^{40}$ Esse é só mais um exemplo, e de modo apoteótico, como a obra de José Camelo e João Melchíades é apresentada através da linguagem do corpo, da voz, da música e das alegorias carnavalescas, num momento de muito brilho que atualiza $O$ pavão misterioso junto ao interesse do grande público ao ponto de conquistar o $2^{\circ}$ lugar na classificação geral ${ }^{41}$.

\section{Permanências e movências}

A obra $O$ pavão misterioso permanece, mas há mobilidade nos textos que são desmaterializados e recriados a cada edição, leituras, usos diferenciados (apropriações) e sentidos produzidos a cada novo contexto. A despeito de ter trilhado tortuosos caminhos, seja quanto à definição de sua autoria ou a quem coube os direitos de sua publicação a cada tempo, tem a vitalidade necessária para alcançar novos patamares de altitude e alcance junto ao público. Por sua vez, é importante destacar que os direitos sobre a obra, no que se refere a João Melchíades, se encontram sob domínio público, mas em relação à autoria de José Camelo ainda não.

De todo modo foi a partir de uma criação bastante original, a ideia de José Camelo, que se construiu um texto matriz e vários outros que daí decorreram. É possível, mesmo, dizer que há uma coautoria, ou recriação mútua, a partir da premissa que ambos se utilizaram da criação do outro. João Melchíades utilizou a ideia e a recriou em um novo texto, reduzindo o de Zé Camelo para 32 páginas. Este, por sua vez, adotou a versão do texto consagrado e a carregou a escrita ali impressa como inteiramente de sua lavra.

\footnotetext{
40 Ver: SAMBA-ENREDO 2012. Cordel Branco e encarnado. Disponível em: <https://www.letras.mus.br/salgueiro-rj/1968141/>. Acesso em 30 abr. 2021.

41 A respeito ver: POETA paraibano é homenageado por escola de samba do Rio. Disponível em: <https://www.jornaldaparaiba.com.br/vida urbana/poeta-paraibano-e-homenageado-por-escola-desamba-do-rio.html>. Acesso em 30 abr. 2021.
} 
No que se refere aos usos diferenciados podemos afirmar que há grande mobilidade de sentidos e a movência recriadora, a partir da grande aceitação do texto em diversos tempos, o fez ter uma dimensão múltipla como expressão artística que vai além do cordel como literatura. Assim dialoga e se retroalimenta na xilogravura popular, na música, no teatro, na novela televisiva e em tantas outras possibilidades. Quanto à impressos, acredita-se que suas muitas edições já tenham mesmo superado a marca de mais de 10 milhões de folhetos publicados em diferentes formatos e recriados em outros textos que dialogam com a matriz em novas leituras. Por sua vez, é importante ressaltar que a circulação se amplia entre os mais diferentes leitores, alcançando com força o público infanto-juvenil, a partir de novas adaptações na forma poética e na linguagem gráfica voltada ao tipo de consumidor e à forma específica de recepção (oral, auditiva, visual, etc.).

Assim, ao mapearmos a trajetória da obra, percebemos o quando a forma do cordel é dinâmica em seus usos diferenciados e como se refaz (e se move) a cada tempo. A partir da oralidade em que foi produzido inicialmente, depois reiterado através da audição da palavra falada e da performance do corpo e da voz, $O$ pavão misterioso se fez escrita. Mas a sua itinerância continua e vai além do suporte papel, pois de modo errante o textoenredo subverte as amarras rígidas da forma e do formato de cordel (sem descaracterizálo em sua poética e potência) e se reinventa a cada tempo como expressão viva de uma literariedade em constante e permanente transformação.

\section{Referências}

A ARTE e o folclore em selo. História de JÔ Oliveira. Disponível em: <https://acervo.museudapessoa.org/pt/conteudo/historia/a-arte-e-o-folclore-em-selos 2910/colecao/www.museudapessoa.net. >. Acesso em: 06 mai. 2021.

Acervo José Paulo Ribeiro. Cópia do recibo de compra de autoria de folhetos de José Camelo de Melo Rezende por Joaquim Batista de Sena. Cartório José Floripes Miranda e Sá - $2^{\circ}$ Tabelião e Oficial de Registros de Títulos e Documentos, da cidade de Guarabira, na Paraíba. 22/05/1954.

Acervo José Paulo Ribeiro. Cópia da autorização de publicação da obra intitulada "O pavão misterioso" pelo proprietário legal Joaquim Batista de Sena à Editora Prelúdio. $11^{\circ}$ Tabelião e Oficial de Registros de Títulos e Documentos da cidade da Guanabara, no Rio de Janeiro. 12/10/1970. 
ADEMAR PAIVA. O pavão misterioso. Direção musical: Djalma Coutinho. São Paulo: FERMATA, 1983. disco sonoro, 33 1/3rpm, estéreo, 12 pol. - Acervo José Paulo Ribeiro.

ALBUQUERQUE, Maria Elizabeth Baltar Carneiro; et. al. Na memória da tradição: fontes de informação em literatura de cordel. Campina Grande: EDUEPB; João Pessoa: Editora da UFPB, 2016.

ALMEIDA Átila; SOBRINHO, José Alves. Dicionário Biobibliográfico de Repentistas e Poetas de Bancada. Campina Grande: Centro de Ciências e Tecnologia; João Pessoa: Editora Universitária, 1978.

URNE, 1981.

Romanceiro Popular Nordestino. Marcos e Vantagens. Campina Grande: UFPB;

ARAÚJO, Alceu Maynard. Literatura de cordel. In: Vida Rotária, São Paulo, n.65, Ano VII, out. 1955.

AZEVEDO, Carlos Alberto. O heroico e o messiânico na literatura de cordel: ensaio de sociologia da literatura. Recife: Edicordel, 1972.

BARROSO, Gustavo. Terra de sol. Natureza e costumes do Norte. Rio de Janeiro: Benjamin de Aguila, 1912.

Ao som da viola. Rio de Janeiro: Livraria Editora Leite Ribeiro, 1921.

BATISTA, Francisco das Chagas. Cantadores e poetas populares. Parahyba: F. C. Baptista Irmão, 1929.

BIDERMAN, Sol. Messianismo e escatologia na literatura de cordel. 1970. Tese (Doutorado). Universidade de São Paulo, Faculdade de Filosofia Ciências e Letras, São Paulo, 1970.

BRANDÃO, Antonio Helonis Borges. Apropriações instituídas e a subversão do popular: usos, formatos e poética do cordel literatura. 2020. $411 \mathrm{f}$. Tese (Doutorado em História Social). Instituto de História, Universidade Federal Fluminense, Niterói, 2020.

CAMELO, José. A afilhada do padre Cícero. [S. 1.]: s. ed., [s.d.]. 16 p. A corrução é assim. Olinda: Casa das Crianças de Olinda, s.d. 8 p. . A india fidalga. [S. l.]: João José Silva, [19- ]. 40 p. A neta de Cancão de Fogo. [S. 1.]: s. ed., s.d. 32 p.

. A peleja de Chica Paculú com o cego Victurino. Guarabira: Liv. e Tip. Lima, [19- ]. $16 \mathrm{p}$. 
CAMELO, José. A verdadeira história de Joãozinho e Mariquinha. [S. 1.]: Sebastião José do Nascimento, s.d. 32 p.

As grandes aventuras de Armando e Rosa conhecidos por "Côco Verde" e "Melancia". Juazeiro do Norte: José Bernardo da Silva, 1964. 32 p.

. Entre o amor e a espada. Juazeiro do Norte: José Bernardo da Silva, 1960. 32 p.

. Entre o amor e a espada. Recife: João Martins de Athayde, 1948. 32 p.

Estória de Aprígio Coutinho e Neusa. Juazeiro do Norte: Manoel Caboclo e Silva, 1975. 40 p.

História da princêsa Adalgisa e o pintor Haroldo de Vilanaz. Fortaleza: Joaquim Batista de Sena, [19--?]. 32 p. 1974. $32 \mathrm{p}$.

História de Pedrinho e Julinha. Juazeiro do Norte: Manoel Caboclo e Silva, . História de três cavalos encantados e três irmãos camponeses. São Paulo: Luzeiro, 1979. 29 p. (Col. Luzeiro. Lit. de Cordel).

História do bom pai e o mau filho. Recife: João José da Silva, s.d. 24 p.

. História do Conde Gaston Marcel e a Duqueza Estelita. [S. 1.]: Manoel T. Barauna, s.d. 32 p.

História do poeta Ramos Patrício e Zulmira Feitosa: sofrimentos, amor e aventura. Guarabira: Tip. Pontes, 1979. 32 p.

. História do poeta Ramos Patrício e Zulmira Feitosa. [S. 1.]: Sebastião José do Nascimento, [s.d.]. 32 p.

. $O$ índio Leão. Campina Grande: A Estrella da Poesia, 1958. 40 p.

. O valor da mulher. Juazeiro do Norte: João Martins de Athayde: José Bernardo da Silva, 1952. 16 p.

. Os martírios de Lelena. Recife: Editora Luzeiro do Norte, [s.d.]. 40 p.

O pavão misterioso. Recife: [s.n.], [19- ]. 32 p.

. O pavão misterioso. [S. 1.]: Ed. Proprietário Joaquim Batista de Sena, [19- ]. 40

p.

. O pavão misterioso em quadrinhos. São Paulo: Prelúdio, s.d. 38 p.

O pavão misterioso. São Paulo: Luzeiro, 1976. 31 p. (Coleção Luzeiro). 
CAMELO, José. O pavão misterioso. São Paulo: Luzeiro, 1980. 32 p.

O pavão misterioso - cordel em quadrinhos. São Paulo: Luzeiro; Fortaleza: Tupynanquim, 2010. $32 \mathrm{p}$.

$32 \mathrm{p}$.

Pedrinho e Julinha. Juazeiro do Norte (CE, BR): José Bernardo da Silva, 1959.

Pedrinho e Julinha. Rio de Janeiro: Academia Brasileira de Literatura de Cordel, 2005. Coleção Cordéis Raríssimos.

CANTEL, Raymond. Temas da atualidade na literatura de cordel. São Paulo: USP\ECA, 1972.

CARVALHO, Rodrigues de. Cancioneiro do Norte. Fortaleza: Tipografia Minerva, 1903.

CASCUDO, Luís da Câmara. Literatura oral no Brasil. Rio de janeiro: José Olympio, 1952.

Cinco livros do povo. Rio de Janeiro: José Olympio, 1953.

CHARTIER, Roger. A história cultural: entre práticas e representações. Lisboa: Difel, 1990.

. Leitura e Cultura Escrita: permanência das obras, mobilidade dos textos, pluralidade das leituras. In: CHARTIER, Roger; RODRIGUES, José Damião; MAGALHÃES, Justino (orgs.). Escritas e cultura na Europa e no Atlântico modernos. Lisboa: Centro de História da Universidade de Lisboa; Instituto de Educação da Universidade de Lisboa, 2020

ENCICLOPÉDIA Itaú Cultural de Arte e Cultura Brasileiras. São Paulo: Itaú Cultural, 2021. Disponível em: <http://enciclopedia.itaucultural.org.br/obra70517/o-romance-dopavao-mysteriozo>. Acesso em: 26 de mai. 2021.

Elias da Paz. Disponível em: <https://www.paraibacriativa.com.br/artista/romano-eliasda-paz/>. Acesso em: 20 abr. 2021.

HISTÓRIA do pavão misterioso. Creuza e Evangelista. Juazeiro do Norte: Tipografia São Francisco, 1949.32 p. - Acervo José Paulo Ribeiro.

INSTITUTO do Patrimônio Histórico e Artístico Nacional. Disponível em: <http://portal.iphan.gov.br/pagina/detalhes/426;http://portal.iphan.gov.br/noticias/detalh es/4833/literatura-de-cordel-e-reconhecida-como-patrimonio-cultural-do-brasil >.

Acesso em: 23 jun. 2021. 
LUCENA, Bruna Paiva de. Espaços em disputa: o cordel e o campo literário brasileiro. 2010. 88 f. Dissertação (Mestrado) - Instituto de Letras, Universidade de Brasília, Brasília, 2010.

LUCIANO, Aderaldo. História crítica do cordel brasileiro. Rio de Janeiro: Edições Adaga; São Paulo: Luzeiro, 2012.

MELO, Rosilene Alves de. Arcanos do verso: trajetória da literatura de cordel. Rio de Janeiro: 7Letras, 2010.

MOTA, Leonardo. Cantadores. Rio de Janeiro: Livraria Castilho, 1921.

Violeiros do Norte. São Paulo: Editora Monteiro Lobato, 1925.

O PAVÃO misterioso. São Paulo: Ed. Graf. Souza, 1959. 32 p.

O PAVÃO misterioso. São Paulo: Ed. Graf. Souza, [s. d.] 32 p.

O PAVÃO misterioso. Campina Grande: Manoel Camilo dos Santos, 1960. 32 p.

O PAVÃO misterioso. São Paulo: Prelúdio, [s.d.]. 29p.

O PAVÃO misterioso. São Paulo: Prelúdio, [s.d.]. 32p.

PAZ, Romano Elias da. A convivencia do Joazeiro e a formalidade do padre Cicero. Guarabira: Typ. e Livraria Pedro Baptista, 1923. 16 p. Heroísmo, amor de infância, Paulino e Helena. [S. 1.]: [s.n.], [s.d.]. 32 p. Peleja de Romano Elias com Azulão. Guarabira: Tip. Pontes, [s.d.]. 23 p.

PEREIRA, Manuel Apolinário. O filho de Evangelista do pavão misterioso. Recife: João José Silva, [s.d.]. 32 p.

O filho de Evangelista do pavão misterioso. São Paulo: Luzeiro, 1980. 32 p.

POETA paraibano é homenageado por escola de samba do Rio. Disponível em: $<$ https://www.jornaldaparaiba.com.br/vida_urbana/poeta-paraibano-e-homenageadopor-escola-de-samba-do-rio.html >. Acesso em: 30 abr. 2021.

PROENÇA, Manoel Cavalcanti. Ribeira do S. Francisco. Rio de Janeiro: Gráfica Laemmert, 1942.

SANTOS, Idelette Muzart- Fonseca. Memória das Vozes: cantoria, romanceiro \& cordel. Salvador: Fundação Cultural do Estado da Bahia, 2006. 
SESC homenageia o cordel com exposição Um olhar contemporâneo do Pavão Misterioso. Disponível em: <https://www.pbagora.com.br/noticia/cultura/seschomenageia-o-cordel-com-exposicao-um-olhar-contemporaneo-do-pavao-misterioso/>. Acesso em: 25 abr. 2021.

SILVA, Gonçalo Ferreira da Silva. Dicionário Brasileiro de Literatura de Cordel. Rio de Janeiro: ABLC, 2005.

SILVA, João Melchiades Ferreira da. Combate de José Colatino com a carranca do Piauí. Campina Grande: Tipografia e Folhetaria Santos, 1955. 16 p.

História do pavão misterioso. Juazeiro do Norte: [s.n.], 1990. 32 p. (Biblioteca Nacional do Cordel).

. O romance do pavão misterioso. Juazeiro do Norte: José Bernardo da Silva, $1959.32 \mathrm{p}$.

$32 \mathrm{p}$.

. O romance do pavão misterioso. Guarabira: Manoel Camilo dos Santos, 1963.

O romance do pavão misterioso. Guarabira: A Estrella da Poesia, 1963. $32 \mathrm{p}$

. O romance do pavão misterioso. Juazeiro do Norte: José Bernardo da Silva, $1981.32 \mathrm{p}$.

O romance do pavão misterioso. [S. 1.]: [s.n.], [s.d.]. 16 p.

. Romance do pavão misterioso. Campina Grande: Ed. Proprietário Manoel Camilo dos Santos: A Estrella da Poesia, 1959. 32 p.

Romance do pavão misterioso: história completa. Juazeiro do Norte: Tip. São Francisco; José Bernardo da Silva, 1961. 32 p.

Romance do pavão misterioso: história completa. Juazeiro do Norte: Tip. São Francisco; José Bernardo da Silva, 1963. 32 p.

. Romance do pavão misterioso: história completa. Juazeiro do Norte: Tip. São Francisco; José Bernardo da Silva, 1965. 32 p.

$32 \mathrm{p}$.

Romance do pavão misterioso. Juazeiro do Norte: José Bernardo da Silva, 1973.

Romance do pavão misterioso. Ilustrações de Stênio. Juazeiro do Norte: José Bernardo da Silva, 1975. 32 p.

. Romance do pavão misterioso. Ilustrações de Stênio. Juazeiro do Norte: Filhas de José Bernardo da Silva, [s.d.]. 32 p. 
SILVA, João Melchiades Ferreira da. Romance do pavão misterioso. Juazeiro do Norte: Lira Nordestina, 2006. 32 p.

Romance do pavão misterioso: história completa. Juazeiro do Norte: Filhas de José Bernardo da Silva: Lira Nordestina, 1981. 32 p.

Romance do pavão misterioso: história completa. Juazeiro do Norte: José Bernardo da Silva, s.d. 32 p. 1978. $32 \mathrm{p}$.

Romance do Pavão mysterioso: história completa. Juazeiro do Norte: [s.n.],

Romance do pavão mysterioso: história completa. Juazeiro do Norte: José Bernardo da Silva, 1981. 32 p.

SOPHIA Biblioteca. Romano Elias da Paz. Disponível em: < http://acervos.casaruibarbosa.gov.br/>. Acesso em: 20 abr. 2021.

TERRA, Ruth Brito Lemos. Memória de lutas: literatura de folhetos do Nordeste (1893 a 1930). São Paulo: Global Editora, 1983.

VIANA, Arievaldo. JOSÉ Camelo de Melo Rezende. Disponível em: <http://www.camarabrasileira.com.br/cordel15.htm>. Acesso em 22 abr. 2021.

A MAIOR polêmica do cordel. Disponível em: $\langle$ http://acordacordel.blogspot.com/2012/02/maior-polemica-do-cordel.html $>$. Acesso em 26 abr. 2021.

ZUNTHOR, Paul. Performance, recepção, leitura. São Paulo: Ubu Editora, 2018.

Artigo recebido em 27 de maio de 2021. Aprovado em 10 de julho de 2021. 